\title{
Alkanindiges illinoisensis gen. nov., sp. nov., an obligately hydrocarbonoclastic, aerobic squalane- degrading bacterium isolated from oilfield soils
}

Correspondence
Bill Bogan
bill.bogan@gastechnology.org

\author{
Bill W. Bogan, ${ }^{1}$ Wendy R. Sullivan, ${ }^{1}$ Kevin J. Kayser, ${ }^{1} \dagger \mathrm{KD}$ Derr, ${ }^{1} \ddagger$ \\ Henry C. Aldrich ${ }^{2}$ and J. Robert Paterek ${ }^{1}$ \\ ${ }^{1}$ Gas Technology Institute, 1700 South Mount Prospect Road, Des Plaines, IL 60018, USA \\ ${ }^{2}$ Department of Microbiology and Cell Science, University of Florida, Box 110700, Bldg 981 \\ Museum Road, Gainesville, FL 32611-0700, USA
}

\begin{abstract}
An alkane-degrading bacterium, designated GTI MVAB Hex $1^{\top}$, was isolated from chronically crude oil-contaminated soil from an oilfield in southern Illinois. The isolate grew very weakly or not at all in minimal or rich media without hydrocarbons. Straight-chain aliphatic hydrocarbons, such as hexadecane and heptadecane, greatly stimulated growth; shorter-chain $\left(\leqslant \mathrm{C}_{15}\right)$ hydrocarbons did not (with decane as the sole exception). Growth was also greatly enhanced by the branched aliphatic hydrocarbons pristane and squalane. The latter of these was most intriguing, as catabolism of squalane has hitherto been reported only for Mycobacterium species. Although unable to utilize mono- or polycyclic aromatic hydrocarbons as sole carbon sources, the isolate did show slight fluorene-mineralizing capability in Luria-Bertani medium, which was partially repressed by hexadecane. In contrast, hexadecane supplementation greatly increased mineralization of ${ }^{14} \mathrm{C}$-dodecane, which was not a growth substrate. Further testing emphasized the isolate's extremely narrow substrate range, as only Tween 40 and Tween 80 supported significant growth. Microscopic examination (by scanning and transmission electron microscopy) revealed a slightly polymorphic coccoidal to bacillar morphology, with hydrocarbon-grown cells tending to be more elongated. When grown with hexadecane, GTI MVAB Hex $1^{\top}$ accumulated a large number of electron-transparent intracytoplasmic inclusion bodies. These were also prevalent during growth in the presence of squalane. Smaller inclusion bodies were observed occasionally with pristane supplementation; they were, however, absent during growth on crude oil. On the basis of 16S rRNA gene sequence data and range of growth substrates, classification of this isolate as the type strain of Alkanindiges illinoisensis gen. nov., sp. nov. is proposed, which is most closely related (approx. $94 \%$ sequence similarity) to Acinetobacter junii.
\end{abstract}

Bacterial biodegradation of crude oil first gained widespread attention as a potential remediation approach in the 1970s (Atlas \& Bartha, 1972; Soli \& Bens, 1972). Many bacteria degrade aliphatic constituents of crude oils, including straight-chain aliphatic hydrocarbons up to $\mathrm{C}_{44}$

Published online ahead of print on 28 February 2003 as DOI 10.1099/ ijs.0.02568-0.

Abbreviations: PAH, polycyclic aromatic hydrocarbon; SEM, scanning electron microscopy; TEM, transmission electron microscopy.

tPresent address: Life Science and High Technology Center, SigmaAldrich, 2909 Lacleide Ave., St Louis, MO 63103, USA.

¥Present address: Vitreous State Laboratory, Catholic University of America, 434 Hannan Hall, 620 Michigan Ave. NE, Washington DC 20064, USA.

The GenBank/EMBL/DDBJ accession number for the 16S rRNA gene sequence of GTI MVAB Hex1 ${ }^{\top}$ is AF513979.
(Sakai et al., 1994; Radwan et al., 1996). Branched-chain alkanes, particularly those with anteiso-terminal branching [substitution on carbon atoms that are immediately adjacent to the terminal carbon atom(s)], are much less susceptible to $\beta$-oxidation (Schaeffer et al., 1979), and thus more recalcitrant, than their unbranched counterparts. Thus, pristane (2,6,10,14-tetramethylpentadecane) was often used as an internal standard to determine biodegradation and weathering of other oil fractions (Alvarez et al., 2001). More recently, however, species of several genera have been shown to biodegrade pristane (McKenna \& Kallio, 1971; Pirnik et al., 1974; Nakajima \& Sato, 1983; Lal \& Khanna, 1996; Alvarez et al., 2001). The longer and more heavily substituted molecule squalane $(2,6,10,15,19,23$ hexamethyltetracosane) has, to date, only been shown to be catabolized by two Mycobacterium species (Berekaa \& Steinbüchel, 2000). 
The work presented herein describes the isolation and initial characterization of a bacterium with a very narrow range of growth substrates, restricted almost completely to long-chain linear and branched aliphatic hydrocarbons, from a chronically heavily contaminated oilfield site in southern Illinois. Soil from this site was contaminated very heavily with crude oil hydrocarbons, with total petroleum hydrocarbon levels that averaged 150000 p.p.m. Samples of soil $(4 \mathrm{~g})$ were added to $50 \mathrm{ml}$ mineral salts medium (MSM) (Bogan et al., 2001a) that contained $800 \mu \mathrm{l}$ hexadecane. After 3 days shaking, enriched cultures were subcultured into fresh hexadecane-supplemented MSM (300 $\mu$ l primary culture: $50 \mathrm{ml}$ medium). After 1 additional day, cultures were plated onto Gelrite plates (Sigma) (Bogan et al., 2001b) overlaid with a thin layer of liquid hexadecane $(100 \mu \mathrm{l})$. Colonies were subcultured onto R2A agar (overlaid with hexadecane) until pure; the isolate, which was given the initial designation GTI MVAB $\mathrm{Hexl}^{\mathrm{T}}$, was identified by sequencing $1533 \mathrm{bp}$ of its $16 \mathrm{~S}$ rRNA gene with primers that spanned positions $5-1540$ in the corresponding Escherichia coli sequence (MIDI). The resultant sequence was compared with those in GenBank by using the BLASTN 2.2.2 algorithm (Altschul et al., 1997).

Based on the 16S rRNA gene sequence of GTI MVAB $\mathrm{Hex} 1^{\mathrm{T}}$, the highest degree of similarity observed (94\%) was to Acinetobacter junii. This was at the lower limit of sequence homology among the 21 recognized Acinetobacter genospecies (Ibrahim et al., 1997), leaving some ambiguity as to whether a confident genus-level match could be made. However, when the 21 sequences used in the above phylogenetic analysis were aligned with the GTI MVAB $\mathrm{Hex}^{\mathrm{T}}$ sequence by using CLUSTAL $\mathrm{W}$ software (Thompson et al., 1994), we observed 36 individual nucleotides that were distributed throughout the sequences which, although strictly conserved among all Acinetobacter strains, diverged in GTI MVAB Hex1 ${ }^{\mathrm{T}}$.

Growth data on decane, dodecane, tetradecane, pentadecane, hexadecane, heptadecane, pristane and squalane (all $>98 \%$ purity) were obtained by using the following method. Wells in a 96-well plate received $150 \mu$ LuriaBertani (LB) broth or MSM medium, $50 \mu \mathrm{l}$ bacterial suspension in MSM $\left(A_{600}\right.$, approx. $\left.0 \cdot 2\right)$ and $5 \mu$ hydrocarbon. Controls (without hydrocarbon) and hydrocarbononly blanks (no inoculum) were included, as were medium-only blanks. Plates were incubated at room temperature with shaking; $A_{600}$ readings were done periodically (MRX-II plate reader; DYNEX Technologies). Cell density was determined by counting aliquots of late exponentialphase hexadecane-grown cultures by using a PetroffHausser counter (Hausser Scientific Partnership) according to the manufacturer's instructions. Ability of the isolate to utilize individual polycyclic aromatic hydrocarbons (PAHs) as sole carbon sources was checked on PAHsublimated gel plates (Alley \& Brown, 2000; Bogan et al., 2001b). Gel plates were supplied with benzene, toluene or naphthalene vapours to assess possible growth on these substrates. Growth on non-petrochemical compounds was assessed by using the Biolog procedure; this test was conducted, using standard methods, by Geneva Laboratories, Elkhorn, WI, USA.

GTI MVAB Hex1 ${ }^{T}$ grew very poorly on plates in the absence of hydrocarbon, producing small $(\sim 0.5 \mathrm{~mm})$, translucent, off-white colonies on R2A agar. No growth was observed on MacConkey agar. Growth was vigorous with an overlayer of liquid hexadecane. When the isolate was subcultured from hexadecane-overlaid plates to R2A plates that lacked hydrocarbon, growth remained vigorous for one to two successive transfers, then decreased, eventually reaching the same poor level that was seen when the isolate was cultured directly onto these plates. Results were the same in liquid culture: GTI MVAB $\mathrm{Hexl}^{\mathrm{T}}$ exhibited essentially no growth in LB broth without liquid hydrocarbon. Growth was greatly enhanced by hexadecane; the isolate was also able to grow in MSM with hexadecane as the sole carbon source. Similar results were observed for heptadecane and octadecane, as well as for the branchedchain aliphatic compounds pristane and squalane (Fig. 1). Exponential-phase doubling times for these substrates were

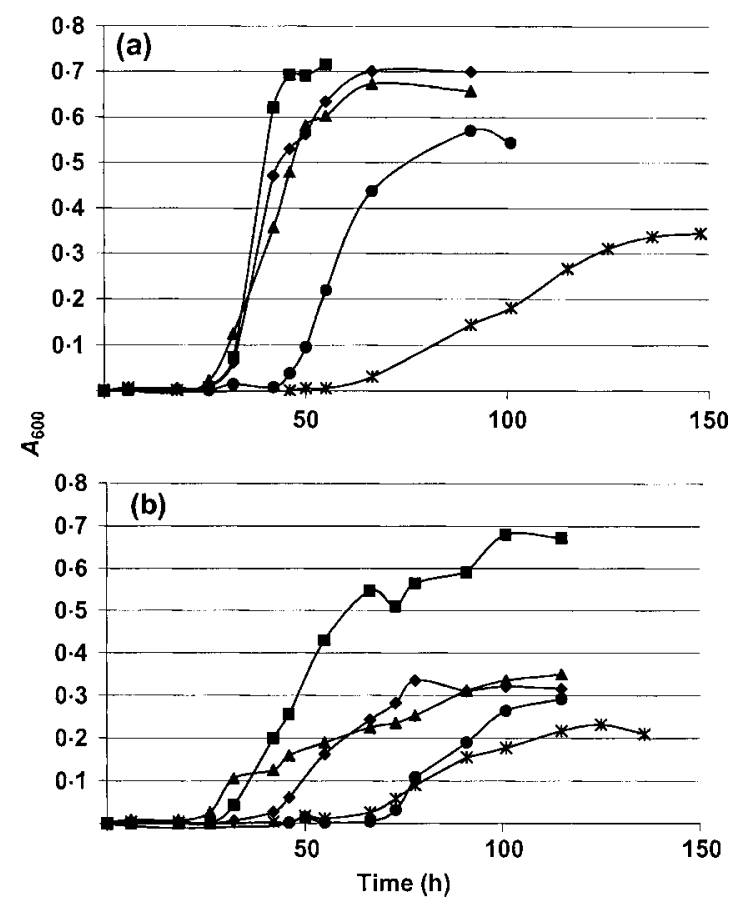

Fig. 1. Growth curves for GTI MVAB Hex1 ${ }^{\top}$ in hydrocarbonsupplemented LB medium (a) or MSM (b). Hydrocarbon addition rate was $\sim 5 \mathrm{mg}$ per well (total culture volume per well, $\sim 150 \mu \mathrm{l})$; medium-only controls did not support growth. Noninoculated (hydrocarbon + medium) control wells were included for each individual condition; no growth occurred in any of these (data not shown). An absorbance value of 1.0 corresponds to a cell density of $3.1 \pm 0.5 \times 10^{9}$ cells ml ${ }^{-1}$. $*$, Decane; $\boldsymbol{\nabla}$, hexadecane; $\boldsymbol{\square}$, heptadecane; $\bullet$, pristane; $\boldsymbol{\Delta}$, squalane. 
generally of the order of $3 \mathrm{~h}$ in LB medium and slightly longer in MSM. Weaker growth occurred on decane; however, no growth was ever observed with hydrocarbons intermediate in length between decane and hexadecane (e.g. dodecane, tetradecane, pentadecane). No growth or PAH-clearing ability was observed on PAH (fluorene, anthracene, phenanthrene or pyrene)-sublimated plates or on gel plates that were exposed to benzene, toluene or naphthalene vapours.

Of the 95 Biolog growth substrates, strong growth was evident only on Tween 40 and Tween 80 . Interestingly, these are the only substrates included in the Biolog system that contain long-chain alkyl moieties within their molecular structures. Weak growth was seen on acetic acid; equivocal results were obtained in the cases of $\alpha$-hydroxybutyric, muconic, $\alpha$-ketobutyric and sebacic acids. Growth was not observed on substrates that are diagnostic for any of the 14 recognized DNA-DNA hybridization groups of Acinetobacter (Bernards et al., 1995). For example, of 14 Acinetobacter genomospecies, 11 have at least one substrate for which every known strain gives a positive reaction; for some cluster groups (e.g. genomospecies 2), the number of such substrates is as high as 24. The only two groups for which this is not true, genomospecies 8 and 12, still have several substrates which give positive reactions for at least $60 \%$ of known strains. The closest 'match' to our results is Acinetobacter johnsonii; however, the substrate range of GTI MVAB $\mathrm{Hexl}^{\mathrm{T}}$ is considerably narrower than that enumerated in the Biolog database for A. johnsonii, which generally $(\geqslant 70 \%$ frequency) gives positive reactions with Tween 40, Tween 80 and acetic acid, but also methylpyruvate $(100 \%$ of isolates), $\alpha$ - and $\beta$-hydroxybutyric acids, lactic acid, propionic acid, bromosuccinic acid, D- and L-alanine, L-proline, L-glutamic acid and L-pyroglutamic acid (Biolog database). Bernards et al. (1995) state that $100 \%$ of Acinetobacter genospecies 7 strains grew on lactic acid, bromosuccinic acid, alanine, asparagine and pyroglutamic acid; none of these yielded a positive reaction for our strain.

One mineralization experiment examined conversion of ${ }^{14} \mathrm{C}$-hexadecane to ${ }^{14} \mathrm{CO}_{2}$ in different media; a second assessed mineralization of an alkane that did not support growth (dodecane), with or without hexadecane. All mineralization experiments were conducted as described previously (Bogan et al., 2001a). Cultures that contained ${ }^{14} \mathrm{C}$-hydrocarbons received approximately 50000 100000 d.p.m. ${ }^{14} \mathrm{C}$ (added in $10 \mu \mathrm{l}$ methanol). Non-labelled hydrocarbons (approx. $10 \mathrm{mg}$ per culture bottle) were added aseptically just prior to inoculation.

GTI MVAB Hex $1^{\mathrm{T}}$ mineralized ${ }^{14} \mathrm{C}$-hexadecane in both MSM and LB broth; mineralization was more rapid and extensive in the latter (Fig. 2). Mineralization of dodecane was very low in LB broth cultures that were supplemented only with the $\mathrm{C}_{12}$ hydrocarbon; approximately $2 \%$ mineralization in 53 days (Fig. 3). This agrees well with the

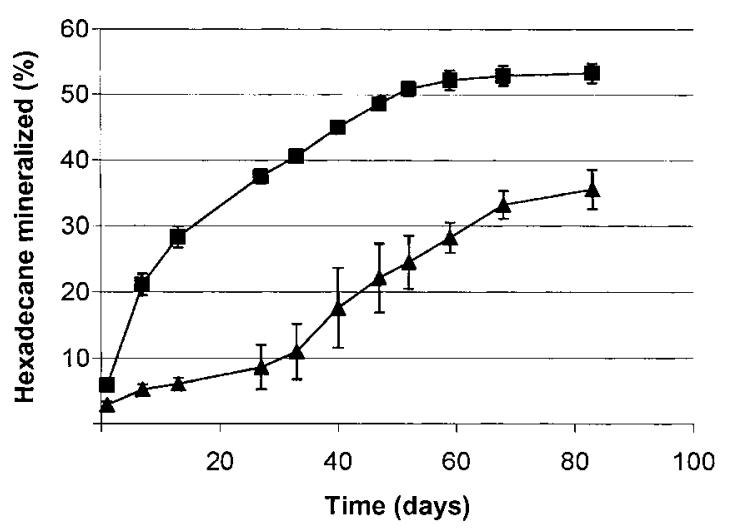

Fig. 2. Mineralization of ${ }^{14} \mathrm{C}$-hexadecane (initial hexadecane concentration, $1.2 \mathrm{mM}$ ) by GTI MVAB $\mathrm{Hex} 1^{\top}$ grown in either mineral salts medium ( $\mathbf{A})$ or LB broth ( $\boldsymbol{\square})$.

growth-substrate data, as dodecane does not support growth when added alone. In contrast, when $10 \mu \mathrm{l}$ hexadecane was added to ${ }^{14} \mathrm{C}$-dodecane-spiked cultures, the amount of ${ }^{14} \mathrm{CO}_{2}$ generated increased approximately sixfold.

Sample preparation for scanning electron microscopy (SEM) was based on previously published methods (Glauert, 1991; Bozzola \& Russell, 1999). Samples were prepared on $0 \cdot 2 \mu \mathrm{m}$ black polycarbonate filters, sputtercoated with gold, before the bacteria were introduced. Bacteria were harvested from agar plates in $50 \mathrm{mM}$ phosphate buffer ( $\mathrm{pH} 7)$. Medium and extracellular debris were removed by five exchanges of phosphate buffer and vacuum filtration. Samples were fixed with $3 \%$ glutaraldehyde in phosphate buffer for $1 \mathrm{~h}$, then washed with phosphate buffer. The secondary fixative was $1 \%$ osmium tetroxide in phosphate buffer for $20 \mathrm{~min}$, again followed by a buffer rinse. After the secondary fix, dehydration was accomplished through a series of ethanol solutions (30, 70, 90, 100 and 100\%); each change of dehydrant

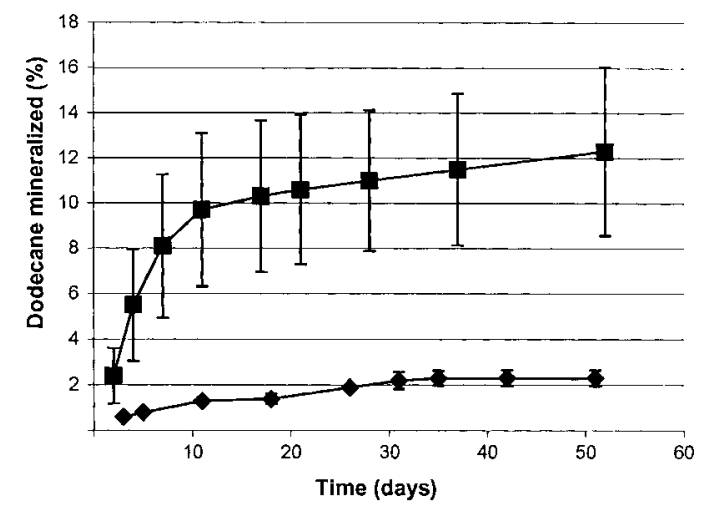

Fig. 3. Mineralization of ${ }^{14} \mathrm{C}$-dodecane, added at the rate of $0.25 \mathrm{mg} \mathrm{ml}^{-1}$, by GTI MVAB Hex $1^{\top}$ grown in LB broth in the presence $(\boldsymbol{\square})$ or absence $(\boldsymbol{)})$ of $1.2 \mathrm{mM}$ hexadecane. 
was held for $20 \mathrm{~min}$. Samples were then dried in a model K850 Critical Point Drier (Emitech) with liquid $\mathrm{CO}_{2}$ as the transitional fluid. Samples were then sputter-coated with gold and viewed by using a Hitachi S3500-N scanning electron microscope. For transmission electron microscopy (TEM), cells on agar plates were fixed (room temperature, $45 \mathrm{~min}$ ) by flooding with $2.5 \%$ glutaraldehyde buffered with $0 \cdot 1 \mathrm{M}$ sodium cacodylate. After buffer washing, cells were fixed with $1 \%$ osmium tetroxide in the same buffer on ice for $45 \mathrm{~min}$, washed with distilled water and stained with $1 \%$ aqueous uranyl acetate $(30 \mathrm{~min})$. Samples were dehydrated in an ethanol series and embedded in Spurr resin. Sections were cut on an LKB Nova ultramicrotome, post-stained with uranyl acetate and lead citrate and observed and photographed on a Zeiss EM-10CA transmission electron microscope.

SEM examination of GTI MVAB Hex $1^{\mathrm{T}}$ revealed a somewhat polymorphic morphology (Fig. 4), with both cocci (diameter, $\sim 0 \cdot 6-0 \cdot 8 \mu \mathrm{m})$ and short bacilli $(0 \cdot 6-0 \cdot 8 \times 1 \cdot 0$ $1.2 \mu \mathrm{m})$ present. When hexadecane-grown cells were visualized by TEM, they were found to contain a large number of electron-transparent inclusion bodies. These were of two types, as seen with Acinetobacter (Scott \& Finnerty, 1976a, b; Ishige et al., 2002) and Rhodococcus (Alvarez et al., 1996). Using the nomenclature from the latter work, we observed both spherical 'ET1' inclusions, which were the predominant inclusion type (Fig. $5 \mathrm{a}-\mathrm{c}$, ef), and non-spherical 'ET2' bodies; the latter were sometimes disc-shaped (Fig. 5b) or irregular in structure (Fig. $5 \mathrm{c}-\mathrm{d}$ ). The largest and most prevalent inclusion bodies were seen in hexadecane-grown cells; frequency and size decreased in squalane-grown cells (Fig. 5e) and diminished further in cells grown on pristane (Fig. 5f). Cells grown in the presence of crude oil or cultured without hydrocarbon contained no inclusions (Fig. $5 \mathrm{~g}$ and h).

Growth of this isolate on pristane and squalane is of particular interest; to date, the only identified species

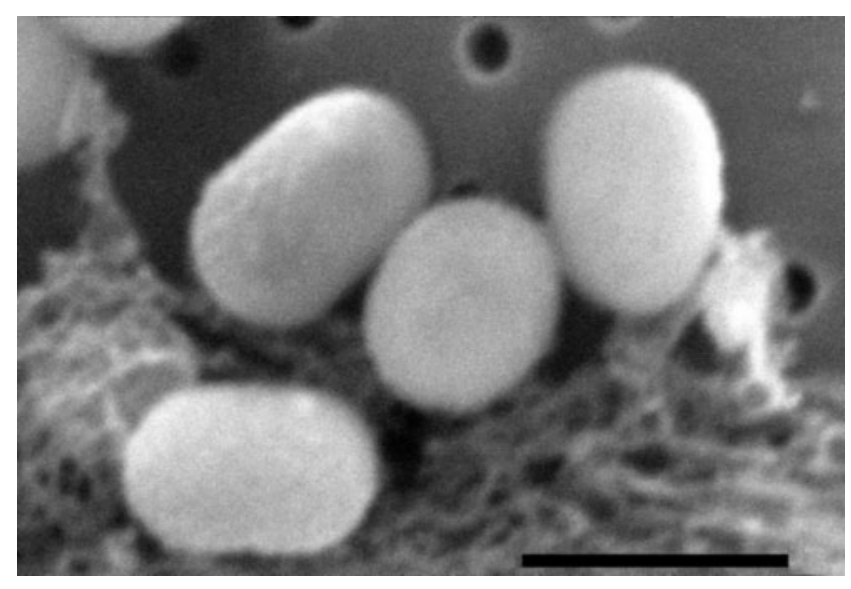

Fig. 4. SEM image of GTI MVAB Hex $1^{\top}$, taken from R2A agar plates. Bar, $1 \mu \mathrm{m}$. capable of growth on squalane have been Mycobacterium fortuitum and 'Mycobacterium ratisbonense' (Berekaa \& Steinbüchel, 2000). The weakness or absence of growth observed with shorter-chain $\left(\mathrm{C}_{10}-\mathrm{C}_{15}\right)$ hydrocarbons is analogous to Arthrobacter nicotianae KCC B35, which grows better on long-chain $\left(\mathrm{C}_{20}-\mathrm{C}_{40}\right)$ alkanes than on shorter $\left(\mathrm{C}_{10}-\mathrm{C}_{18}\right)$ aliphatic hydrocarbons (Radwan et al., 1996). KCC B35 was isolated from a post-Gulf War environment in which many of the short-chain aliphatic constituents of oil spills had been biodegraded and/or removed via weathering, leaving a disproportionate amount of heavy alkanes. GTI MVAB Hexi ${ }^{\mathrm{T}}$ can clearly take up and catabolize non-growth-supporting alkanes (at least dodecane - Fig. 2b); failure to grow on these hydrocarbons may indicate that one or more of the strain's alkanedegrading enzymes is only induced by aliphatic hydrocarbons with chain lengths of $\mathrm{C}_{16}$ or above.

Such a limited growth-substrate range for a hydrocarbondegrading bacterium is fairly rare. Thermophilic bacteria are known to possess this trait occasionally (Merkel et al., 1978; Zarilla \& Perry, 1984). Among non-thermophiles, however, we are only aware of two instances in which a bacterial strain has been documented to be as obligately hydrocarbonoclastic as GTI MVAB Hex1 ${ }^{\mathrm{T}}$. One such strain, related to Alcaligenes, grew on $\mathrm{C}_{9}-\mathrm{C}_{18}$ alkanes but was unable to utilize any of the sugars or amino acids against which it was tested (Bertrand et al., 1976a); this strain did, however, grow on propionic acid (Bertrand et al., 1976b), which GTI MVAB $\mathrm{Hexl}^{\mathrm{T}}$ is unable to utilize. Furthermore, the range of potential substrates against which this strain was screened was far less broad than the 95 substrates employed in the Biolog procedure. Cabezalí and coworkers isolated 'many' strains of hydrocarbondegraders from the Bahía Blanca estuary; one of these was capable of growth only on linear alkanes, fatty acids and ethanol (Cabezalí \& Cubitto, 1990; Cubitto \& Cabezalí, 1994). Like GTI MVAB Hex $1^{\mathrm{T}}$, both of the above-described strains were isolated from chronically oil-polluted sites. Taken together, these findings suggest that chronically petrochemical-contaminated sites may have a high propensity for giving rise to bacteria that can only grow on petrogenic hydrocarbons.

The 16S rRNA gene sequence of GTI MVAB Hex1 ${ }^{\mathrm{T}}$ places it outside existing genera and differs from the closest Acinetobacter species (A. junii) by approximately $6 \%$, which roughly equals the maximum amount of divergence seen among the 21 genospecies of Acinetobacter (Ibrahim et al., 1997). However, our isolate diverged at 36 positions that were strictly conserved among all Acinetobacter sequences; thus, we are confident that it belongs outside this genus. Only one $16 \mathrm{~S}$ rRNA sequence in GenBank exhibits sufficient identity to GTI MVAB Hex1 $1^{\mathrm{T}}$ to be considered possibly congeneric; the partial (339 bp) sequence (accession no. Z69268) of a groundwater bacterium (JN3c) from an alkaline spring at Maqarin, Jordan, displayed $99 \cdot 1 \%$ similarity to that of GTI MVAB Hex1 ${ }^{\mathrm{T}}$. Furthermore, a 

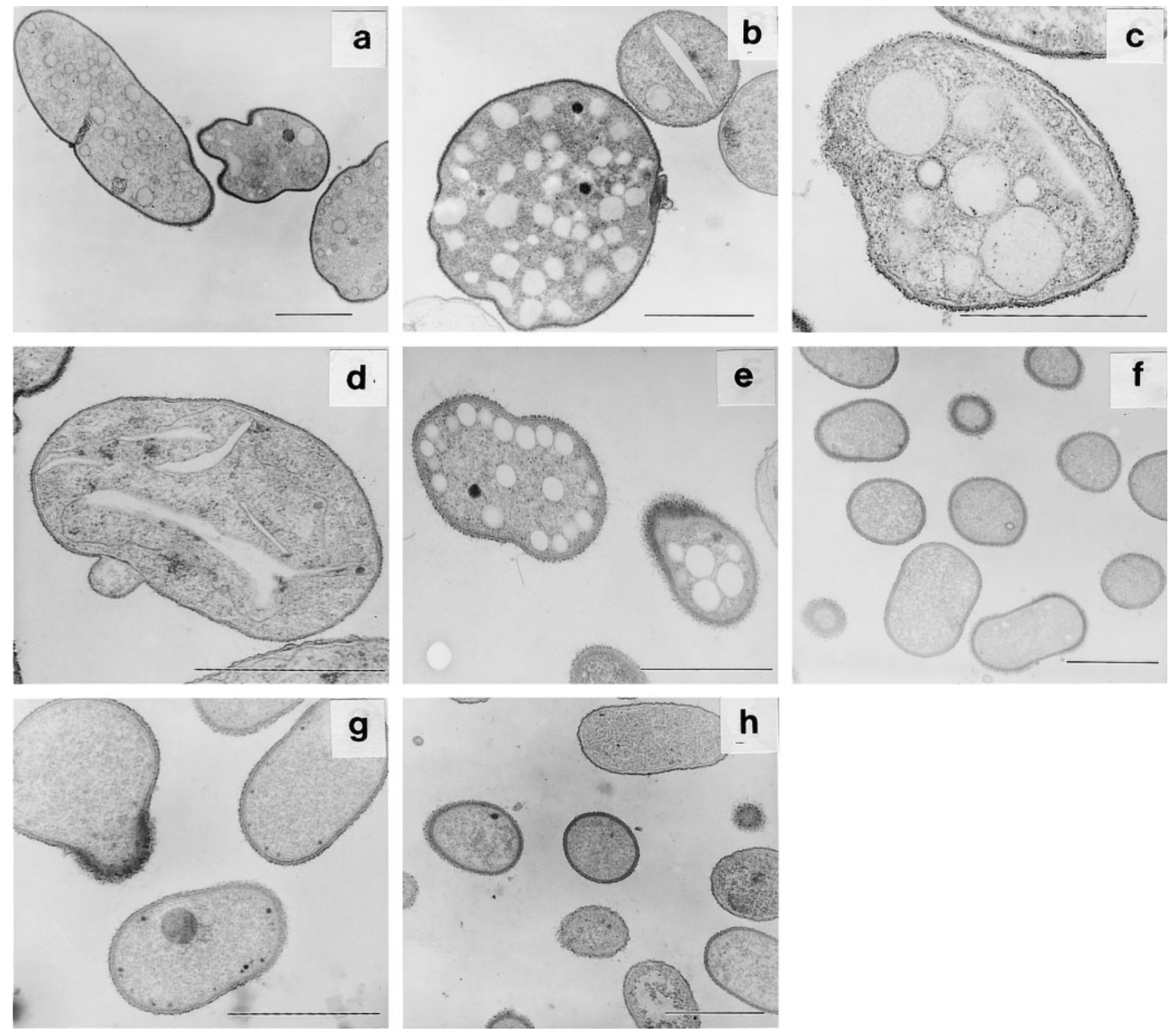

Fig. 5. TEM images of GTI MVAB Hex $1^{\top}$. All cells were taken from R2A agar plates after 3-5 days growth in the presence or absence of liquid hydrocarbon overlay. (a) Hexadecane-grown cells showing a large number of small, spherical 'ET1'-type inclusion bodies. Hexadecane-grown cells were also observed to accumulate disc-shaped to amorphous 'ET2' wax ester inclusions, either alone (b) or together with ET1 bodies (c). (d) ET2-containing cell in which inclusion bodies show evidence of intracellular membranes. (e) Squalane-supplemented cells showing ET1 inclusions, which also occurred (albeit smaller and more rarely) in cells cultured on pristane ( $\mathrm{f}$ ). Crude oil-grown cells $(\mathrm{g})$ and those grown in the absence of hydrocarbon ( $\mathrm{h}$ ) lacked detectable inclusions. Bars, $1 \mu \mathrm{m}$.

BLAST search reveals that the JN3c sequence, like that of GTI MVAB Hex1 $1^{\mathrm{T}}$, exhibits no more than $94 \%$ similarity to any other sequence in GenBank; included among those that matched JN3 $\mathrm{C}$ at this level were numerous Acinetobacter strains. The JN3c bacterium, however, has so far not been cultured and the sequence information was obtained exclusively by isolating environmental DNA (Dr Karsten Pedersen, Göteborg University, personal communication); therefore, the strain is not available for direct comparison.

\section{Description of Alkanindiges gen. nov.}

Alkanindiges (Al.kan.in.di'ges. N.L. neut. n. alkanum alkane; L. adj. indiges in need; N.L. masc. n. Alkanindiges the alkane-requiring one, indicating the bacterium's growth requirement for such hydrocarbons).

Aerobic cocci to short rods. Gram-variable, probably due to extensive extracellular coat (see species description below). Sporulation has not been observed. In both liquid 
and solid media, growth is very poor in the absence of linear alkane hydrocarbons with chain-length below $\mathrm{C}_{16}$. The type and only species described to date is Alkanindiges illinoisensis, although an as-yet-uncultured bacterium, JN3c, may be congeneric.

\section{Description of Alkanindiges illinoisensis sp. nov.}

Alkanindiges illinoisensis (il.li.nois.en'sis. N.L. gen. n. illinoisensis pertaining to Illinois, the state from which the type strain was isolated).

In addition to the properties described for the genus, cells are non-motile and catalase-positive. Colonies formed on R2A agar in the absence of hydrocarbon are small and colourless to translucent cream-coloured. Sugars are not hydrolysed and the isolate is non-haemolytic. Substrates that support good growth include hexadecane, heptadecane, pristane, squalane and Tween surfactants. Weak growth occurs on acetic acid; no other substrate in the Biolog test gave unequivocally positive growth. Morphologically, cells occur as both spheres and short rods with dimensions of $0 \cdot 9-1 \cdot 6 \times 1 \cdot 5-2.5 \mu \mathrm{m}$. Based on TEM observations of hydrocarbon-grown cells, plasma membrane, peptidoglycan and outer membrane structures are similar to those of Gram-negative strains, with an extensive layer of extracellular matrix often present. During rapid growth on hydrocarbons (especially hexadecane), extensive accumulation of large intracellular inclusion bodies is observed.

The type strain is GTI MVAB Hexl ${ }^{\mathrm{T}}$ (=ATCC PTA$4839^{\mathrm{T}}=$ DSM $\left.15370^{\mathrm{T}}\right)$.

\section{Acknowledgements}

This work was conducted with support from the United States Department of Energy and the Gas Research Institute. Lorraine McDowell gave expert assistance with TEM.

\section{References}

Alley, J. F. \& Brown, L. R. (2000). Use of sublimation to prepare solid microbial media with water-insoluble substrates. Appl Environ Microbiol 66, 439-442.

Altschul, S. F., Madden, T. L., Schäffer, A. A., Zhang, J., Zhang, Z., Miller, W. \& Lipman, D. J. (1997). Gapped BLAST and PSI-BLAST: a new generation of protein database search programs. Nucleic Acids Res 25, 3389-3402.

Alvarez, H. M., Mayer, F., Fabritius, D. \& Steinbüchel, A. (1996). Formation of intracytoplasmic lipid inclusions by Rhodococcus opacus strain PD630. Arch Microbiol 165, 377-386.

Alvarez, H. M., Souto, M. F., Viale, A. \& Pucci, O. H. (2001). Biosynthesis of fatty acids and triacylglycerols by 2,6,10,14tetramethyl pentadecane-grown cells of Nocardia globerula 432. FEMS Microbiol Lett 200, 195-200.

Atlas, R. M. \& Bartha, R. (1972). Degradation and mineralization of petroleum by two bacteria isolated from coastal waters. Biotechnol Bioeng 14, 297-308.
Berekaa, M. M. \& Steinbüchel, A. (2000). Microbial degradation of the multiply branched alkane 2,6,10,15,19,23-hexamethyltetracosane (squalane) by Mycobacterium fortuitum and Mycobacterium ratisbonense. Appl Environ Microbiol 66, 4462-4467.

Bernards, A. T., Dijkshoorn, L., Van der Toorn, J., Bochner, B. R. \& Van Boven, C. P. (1995). Phenotypic characterization of Acinetobacter strains of 13 DNA-DNA hybridisation groups by means of the Biolog system. J Med Microbiol 42, 113-119.

Bertrand, J. C., Mutafschiev, S., Henkel, H. G., Bazin, H. \& Azoulay, E. (1976a). Isolation and study of a new marine bacterium growing on hydrocarbons. I. Physiological study. Ann Microbiol (Paris) 127B, 373-391 (in French).

Bertrand, J. C., Bazin, H. \& Azoulay, E. (1976b). Isolation and study of a new marine bacterium growing on hydrocarbons. II. Mechanism of lysis and viability. Ann Microbiol (Paris) 127B, 393-409 (in French).

Bogan, B. W., Lahner, L. M., Trbovic, V., Szajkovics, A. M. \& Paterek, J. R. (2001a). Effects of alkylphosphates and nitrous oxide on microbial degradation of polycyclic aromatic hydrocarbons. Appl Environ Microbiol 67, 2139-2144.

Bogan, B. W., Lahner, L. M. \& Paterek, J. R. (2001b). Limited roles for salicylate and phthalate in bacterial $\mathrm{PAH}$ bioremediation. Bioremed J 5, 93-100.

Bozzola, J. J. \& Russell, L. D. (1999). Electron Microscopy: Principles and Techniques for Biologists, 2nd edn. Sudbury, MA: Jones \& Bartlett.

Cabezali, C. B. \& Cubitto, M. A. (1990). Detcción bacteriológica de contaminación por petróleo en el estuario de Bahía Blanca. Rev Argent Microbiol 22, 167-174 (in Spanish).

Cubitto, M. A. \& Cabezali, C. B. (1994). Marine bacterium capable of preferential growth on hydrocarbons isolated from Bahía Blanca estuary. Microbios 77, 15-18.

Glauert, A. M. (1991). Fixation, Dehydration and Embedding of Biological Specimens. Amsterdam: Elsevier.

Ibrahim, A., Gerner-Smidt, P. \& Liesack, W. (1997). Phylogenetic relationship of the twenty-one DNA groups of the genus Acinetobacter as revealed by $16 \mathrm{~S}$ ribosomal DNA sequence analysis. Int J Syst Bacteriol 47, 837-841.

Ishige, T., Tani, A., Takabe, K., Kawasaki, K., Sakai, Y. \& Kato, N. (2002). Wax ester production from $n$-alkanes by Acinetobacter sp. strain M-1: ultrastructure of cellular inclusions and role of acyl coenzyme A reductase. Appl Environ Microbiol 68, 1192-1195.

Lal, B. \& Khanna, S. (1996). Degradation of crude oil by Acinetobacter calcoaceticus and Alcaligenes odorans. J Appl Bacteriol 81, 355-362.

McKenna, E. J. \& Kallio, R. E. (1971). Microbial metabolism of the isoprenoid alkane pristane. Proc Natl Acad Sci U S A 68, 1552-1554.

Merkel, G. J., Underwood, W. H. \& Perry, J. J. (1978). Isolation of thermophilic bacteria capable of growth solely on long-chain hydrocarbons. FEMS Microbiol Lett 3, 81-83.

Nakajima, K. \& Sato, A. (1983). Microbial metabolism of the isoprenoid alkane pristane. Nippon Nogeikagaku Kaishi 57, 299-305.

Pirnik, M. P., Atlas, R. M. \& Bartha, R. (1974). Hydrocarbon metabolism by Brevibacterium erythrogenes: normal and branched alkanes. J Bacteriol 119, 868-878.

Radwan, S. S., Sorkhoh, N. A., Felzmann, H. \& El-Desouky, A.-F. (1996). Uptake and utilization of $n$-octacosane and $n$-nonacosane by Arthrobacter nicotianae KCC B35. J Appl Bacteriol 80, 370-374.

Sakai, Y., Maeng, J. H., Tani, Y. \& Kato, N. (1994). Use of long-chain $n$-alkanes $\left(\mathrm{C}_{13}-\mathrm{C}_{44}\right)$ by an isolate, Acinetobacter sp. M-1. Biosci Biotechnol Biochem 58, 2128-2130. 
Schaeffer, T. L., Cantwell, S. G., Brown, J. L., Watt, D. S. \& Fall, R. R. (1979). Microbial growth on hydrocarbons: terminal branching inhibits biodegradation. Appl Environ Microbiol 38, 742-746.

Scott, C. C. L. \& Finnerty, W. R. (1976a). A comparative analysis of the ultrastructure of hydrocarbon-oxidizing micro-organisms. J Gen Microbiol 94, 342-350.

Scott, C. C. L. \& Finnerty, W. R. (1976b). Characterization of intracytoplasmic hydrocarbon inclusions from the hydrocarbonoxidizing Acinetobacter species HO1-N. J Bacteriol 127, 481-489.
Soli, G. \& Bens, E. M. (1972). Bacteria which attack petroleum hydrocarbons in a saline medium. Biotechnol Bioeng 14, 319-30.

Thompson, J. D., Higgins, D. G. \& Gibson, T. J. (1994). CLUSTAL W: improving the sensitivity of progressive multiple sequence alignment through sequence weighting, position-specific gap penalties and weight matrix choice. Nucleic Acids Res 22, 4673-4680.

Zarilla, K. A. \& Perry, J. J. (1984). Thermoleophilum album gen. nov. and sp. nov, a bacterium obligate for thermophily and $n$-alkane substrates. Arch Microbiol 137, 286-290. 